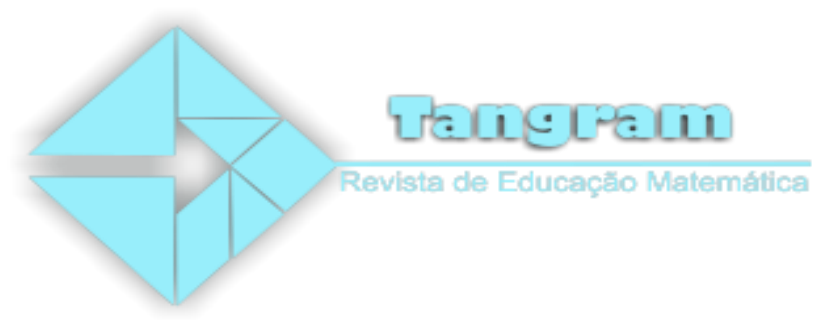

\title{
Apresentação: Currículo, possibilidades de ensino e formação de professores em matemática
}

Esta edição conta com 7 investigações organizadas em artigos investigativos, iniciação científica e relatos de experiência. Temos 5 artigos científicos, 4 de diferentes instituições brasileiras (Paraná, Rio de Janeiro, Ceará, Rio Grande do Norte e Minas Gerais) e um artigo estrangeiro (Peru) Divulgamos ainda uma iniciação científica e um relato de experiência ambos desenvolvidos em São Paulo.

De modo geral, identificamos que os artigos trazem contribuições para o ensino e aprendizagem de Matemática e permitem refletirmos sobre os documentos curriculares e propostas de ensino e de formação de professores.

Assim, o artigo de Luís Felipe Gonçalves Carvalho,Bruno Pereira de Matos Silva,John Anderson Ferreira Pereira,Chang Kuo Rodrigues intitulado "Educação Financeira em Situações de Ensino e de Aprendizagem: Momentos de Reflexão" iniciam a edição apresentando como estudantes da educação básica controlam suas finanças e quais as relações que os estudantes possuem com a educação financeira.

O segundo artigo intitulado "Educação Financeira para estudantes da Educação Superior" escrito por Francisca Tuanny Aparecida de Souza Silva, Aylla Gabriela Paiva de Araújo, Francisco Ronald Feitosa Moraes, Francisco Régis Vieira Alves apresentam os resultados de minicursos desenvolvidos sobre Educação Financeira, identificando que os cursistas começaram a utilizar os conhecimentos adquiridos sobre educação financeira em hábitos cotidianos.

A terceira pesquisa de Daysi Julissa García-Cuéllar,Jesús Victoria Flores Salazar, intitulada "Estudio de la génesis instrumental del artefacto simbólico simetría axial" trazem uma releitura da dissertação de mestrado da primeira autora, apresentando reflexões instrumentalização do objeto matemático da simetria axial para estudantes de 12 e 13 anos da educação básica.

O artigo “A identificação da Função Logarítmica num trabalho com o software GeoGebra e futuros professores de Matemática", escrito por Luciano Ferreira, Mariana

Tangram - Revista de Educação Matemática, Dourados - MS - v.2 n. 3, pp. 01-02 (2019) 
Moran, Valdeni Soliani Franco apresentam uma sequência didática utilizando o software Geogebra, permitindo refletir sobre o uso da tecnologia para o ensino.

Assim, o quinto artigo científico intitulado "Investigações geométricas em sala de aula: (re) construindo o conceito de área no geoplano com o teorema de Pick" de autoria de Eliane Scheid Gazire, Sabrina Alves Boldrini Cabral ,Bruna das Graças Ferreira Soares Teixeira. As autoras apresentam um estudo do conceito geométrico por meio do uso do Geoplano.

O sexto artigo trata-se de uma investigação de iniciação cientifica, intitulada "BNCC do Ensino Médio: um olhar sobre os conteúdos de área e volume nos livros didáticos de Matemática" de autora de Brena Cristina Sturion, Rúbia Barcelos Amaral-Schio analisam o conteúdo de área e volume em três coleções de livros didáticos de matemática Ensino Médio aprovados no PNLD 2018 relacionando os conceitos apresentados na Base Nacional Comum Curricular (BNCC).

O último artigo é um relato de experiência intitulado "A ludicidade no ensino de frações para alunos com necessidades especiais: cegueira", escrito por Valdete Ap. do Amaral Miné, Maria Dolores M. C. Coutinho. As autoras relatam a experiência de ensinar frações a uma aluna cega.

Assim, desejamos uma boa leitura à todos

Editores

Edvonete Souza de Alencar

Tiago Dziekaniak Figueiredo

Aldrin Cleyde da Cunha

Adriana Fátima de Souza Miola

Tangram - Revista de Educação Matemática, Dourados - MS - v.2 n. 3, pp. 01-02 (2019) 